\title{
Numerical Simulation and Performance Analysis of Twin Screw Air Compressors
}

 \\ a Department of Air Conditioning and Refrigeration, National Taipei University of Technology, Taipei, Taiwan 106, ROC; \\ ${ }^{\mathrm{b}}$ Department of Mechanical Engineering, National Taiwan University, Taipei, Taiwan 106, ROC, \\ ${ }^{\mathrm{c}} \mathrm{Fu}$ Sheng Industrial Co. Ltd., No. 60, Sec. 2, Kwang-Fu Rd., Sanchung, Taiwan 241, ROC
}

(Received 15 October 1998; In final form 6 August 1999)

\begin{abstract}
A theoretical model is proposed in this paper in order to study the performance of oil-less and oil-injected twin screw air compressors. Based on this model, a computer simulation program is developed and the effects of different design parameters including rotor profile, geometric clearance, oil-injected angle, oil temperature, oil flow rate, built-in volume ratio and other operation conditions on the performance of twin screw air compressors are investigated. The simulation program gives us output variables such as specific power, compression ratio, compression efficiency, volumetric efficiency, and discharge temperature. Some of the above results are then compared with experimentally measured data and good agreement is found between the simulation results and the measured data.
\end{abstract}

Keywords: Twin screw compressor, Performance simulation, Compression ratio, Specific power, Built-in volume ratio, Compression efficiency

\section{INTRODUCTION}

The twin screw air compressor is a positive displacement compressor. It utilizes the continual variations of the space formed between rotor grooves and case of the compressor to compress gas. In the early stage of development, the compression process of a twin screw compressor was usually estimated empirically. The drawbacks of the empirical process were time consuming, difficult to attain an optimal performance, and requiring real model tests.
Many mathematical models for the performance analysis of a twin screw compressor have been proposed. Bein and Hamilton (1982) presented a theoretical model for an oil-injected screw air compressor. They utilized a polytropic compression process model to find the value of the polytropic constant that assured the highest consistency of the model results as well as the experimental data. Sångfors (1982) studied both oil-less and oilinjected twin screw compressors. By taking into account the dynamic loss, leakage and heat transfer, he used R12 and air as the working fluid and

\footnotetext{
*Corresponding author. Tel.: 886-2-2771-2171, ext. 3515. Fax: 886-2-2731-4919. E-mail: f10911@ntut.edu.tw.
} 
developed a numerical method to predict variations of internal state of the compressor. Singh and Bowman (1986) have discussed the effects of parameters such as gear tooth form and gear tooth number in a pair of female and male rotors on the performance of an oil-injected compressor. To make a model adaptable to assorted kinds of fluid, Xiao et al. (1986) has presented a theoretical model taking into account the real gas effect, leakage, heat transfer and flow resistance of the discharged gas. Geometric profiles such as length of the gas-seal line and orifice area of the discharge valve were also considered in the model. Recently, Fujiwara and Osada (1995) have applied both numerical method and experimental measurement to study the performance of a twin screw air compressor.

To evaluate the performance of twin screw air compressors, an effort has been made to develop a general theoretical model accompanying with its computer simulation program in the present study. The theoretical model takes into consideration most merits of the above mentioned papers. In particular, the effects of geometric clearance, oilor water-injected angle, oil or water temperature, gas leakage, heat transfer between oil and air, and mass transfer between water and air are considered. Aside from the theoretical study, experimental data were measured in a test laboratory in order to verify the simulation program with measured data. Once the theoretical model is justified, the optimum operation condition of a twin screw air compressor which is helpful in design can be well mastered.

\section{MATHEMATICAL MODEL}

As shown in Fig. 1, the compression chamber of a twin screw air compressor is a space encompassed by the male rotor groove, female rotor groove and the case. In general, there are several compression chambers between a pair of male and female rotors. In a particular compression chamber, the state of gas is related only to the rotational angle of the rotor when the motion is in steady state. It also indicates that when the compression chambers rotate to an angle of the same degrees, they all have the same temperature, pressure, mass, etc. Based on this assumption, the following derivations are introduced within a compression chamber.

\section{Governing Equations}

Since the intrinsic state and property of the two fluids contained in the control volume are not identical, it is required to derive the governing equations for the gas and oil respectively. With regarding to the gas, the following equations are derived by the consideration of conservation of mass and energy:

$$
\frac{\mathrm{d} m_{\mathrm{g}}}{\mathrm{d} \theta_{\mathrm{m}}}=\frac{1}{\omega_{\mathrm{m}}}\left(\sum_{k=1}^{n 1} \dot{m}_{\mathrm{gik}}-\sum_{k=1}^{n 2} \dot{m}_{\mathrm{gok}}\right),
$$

$$
\begin{aligned}
\frac{\mathrm{d} T_{\mathrm{g}}}{\mathrm{d} \theta_{\mathrm{m}}}= & \frac{1}{\omega_{\mathrm{m}} m_{\mathrm{g}} C_{V, \mathrm{~g}}}\left\{-T_{\mathrm{g}}\left(\frac{\partial P}{\partial T}\right)_{V}\left[\omega_{\mathrm{m}} \frac{\mathrm{d} V}{\mathrm{~d} \theta_{\mathrm{m}}}\right.\right. \\
& \left.+\frac{1}{\rho_{\mathrm{l}}}\left(\dot{m}_{\mathrm{lo}}-\dot{m}_{\mathrm{li}}\right)\right]+\sum_{k=1}^{n 1} i_{\mathrm{gik}} \dot{m}_{\mathrm{gik}} \\
& +\left[\frac{V-m_{\mathrm{l}} / \rho_{\mathrm{l}}}{m_{\mathrm{g}}} T_{\mathrm{g}}\left(\frac{\partial P}{\partial T}\right)_{V}-i_{\mathrm{g}}\right] \sum_{k=1}^{n 1} \dot{m}_{\mathrm{gik}} \\
& -\frac{V-m_{\mathrm{l}} / \rho_{\mathrm{l}}}{m_{\mathrm{g}}} T_{\mathrm{g}}\left(\frac{\partial P}{\partial T}\right)_{V} \sum_{k=1}^{n 2} \dot{m}_{\mathrm{go} k} \\
& \left.-h A\left(T_{\mathrm{g}}-T_{\mathrm{l}}\right)\right\},
\end{aligned}
$$

where $n 1$ and $n 2$ represent the total number of inlet and outlet channels including suction valve orifice, discharge valve orifice and leaking path. These channels allow gas to enter into and discharge from the control volume.

With regarding to the oil, the following equations can be derived based on conservation of 




FIGURE 1 Geometry of a twin screw air compressor.

mass and energy:

$$
\begin{aligned}
& \frac{\mathrm{d} m_{1}}{\mathrm{~d} \theta_{\mathrm{m}}}=\frac{1}{\omega_{\mathrm{m}}}\left(\sum_{k=1}^{n 3} \dot{m}_{\mathrm{lik}}-\sum_{k=1}^{n 4} \dot{m}_{\mathrm{lok}}\right), \\
& \frac{\mathrm{d} T_{1}}{\mathrm{~d} \theta_{\mathrm{m}}}=\frac{1}{\omega_{\mathrm{m}} m_{\mathrm{l}} C_{V, 1}}\left\{C_{V, 1} \sum_{k=1}^{n 3}\left(T_{\mathrm{lik}}-T_{1}\right) \dot{m}_{\mathrm{lik}}\right. \\
&\left.-h A\left(T_{1}-T_{\mathrm{g}}\right)\right\},
\end{aligned}
$$

where $n 3$ and $n 4$ represent the total number of inlet and outlet channels such as oil-injected orifice, discharge valve orifice and leaking path.

\section{Suction Process}

In the suction process, since area of the suction valve orifice is large enough to slow down the flowing speed of gas, the pressure loss during gas flowing is negligible. Therefore, the mass flow rate of the suction gas can be considered as $\dot{m}=$ $A_{\text {vi }} \sqrt{2 \rho\left(P_{\mathrm{s}}-P\right)}$, in which $A_{\mathrm{vi}}$ denotes area of the suction orifice.

\section{Discharge Process}

The difference between the gas pressure in a compression chamber and the system back pressure is the major pressure loss when gas passes through an orifice. Therefore, the flow rate in the discharge process can be calculated as $\dot{m}=$ $C_{\mathrm{D}} A_{\text {vo }} \sqrt{2 \rho\left|P-P_{\mathrm{d}}\right|}$, in which $A_{\text {vo }}$ indicates the orifice area of a discharge valve. The total flow rate is the summation of all flow rates of the gas passing through various orifices with different ratios of opening areas. 
As gas and oil are discharged simultaneously, the mass flow rates of gas and oil, respectively, are

$$
\begin{gathered}
\dot{m}_{\mathrm{g}}= \begin{cases}\frac{-\dot{m}}{1+\phi}, & P \geq P_{\mathrm{d}}, \\
\dot{m}, & P<P_{\mathrm{d}},\end{cases} \\
\dot{m}_{1}= \begin{cases}\frac{-\phi \dot{m}}{1+\phi}, & P \geq P_{\mathrm{d}}, \\
0, & P<P_{\mathrm{d}},\end{cases}
\end{gathered}
$$

in which $\phi$ indicates the ratio of oil mass to gas mass, i.e., $\phi=m_{\mathrm{l}} / m_{\mathrm{g}}$.

\section{Gas Leakage Model}

Gas leakage is one of the vital factors that affect the performance of an air compressor. The calculation of leakage also affects the simulation accuracy of the compressor. In a twin screw air compressor, there are four major leaking paths, namely blowhole, clearance between two rotors, clearance between rotor tip and case, and clearance between end plate and case. In general, it is very difficult to obtain the precise amount of leakage from experiments. The convergent nozzle model is therefore adopted herein to account for the leakage. It states that

$\dot{m}=C_{\mathrm{D}} A_{\mathrm{c}} P_{\mathrm{h}}$

$$
\begin{aligned}
& \times \sqrt{\frac{2 \beta}{\beta-1} \frac{1}{R_{\mathrm{m}} T_{\mathrm{h}}}\left[\left(\frac{P_{1}}{P_{\mathrm{h}}}\right)^{2 / \beta}-\left(\frac{P_{1}}{P_{\mathrm{h}}}\right)^{(\beta+1) / \beta}\right]} \\
& \text { when }\left(\frac{2}{\beta+1}\right)^{\beta /(\beta-1)}<\frac{P_{1}}{P_{\mathrm{h}}}<1
\end{aligned}
$$

and

$$
\begin{gathered}
\dot{m}=C_{\mathrm{D}} A_{\mathrm{c}} P_{\mathrm{h}} \sqrt{\frac{\beta}{R_{\mathrm{m}} T_{\mathrm{h}}}\left(\frac{2}{\beta+1}\right)^{(\beta+1) /(\beta-1)}} \\
\text { when } 0<\frac{P_{1}}{P_{\mathrm{h}}}<\left(\frac{2}{\beta+1}\right)^{\beta /(\beta-1)},
\end{gathered}
$$

in which $P_{1}$ and $P_{\mathrm{h}}$ are the lower pressure and higher pressure of the adjacent grooves, $C_{\mathrm{D}}$ is the coefficient of flow rate, $\beta$ is the specific heat ratio, and $R_{\mathrm{m}}$ is the revised gas constant. The last two variables can be calculated as

$$
\beta=\frac{C_{P}+\phi C_{V, 1}}{C_{V}+\phi C_{V, 1}} \quad \text { and } \quad R_{\mathrm{m}}=\frac{1}{1+\phi} R .
$$

\section{Heat Transfer between Oil and Gas}

Heat transfer is another vital factor that affects the performance of an air compressor. It is very difficult to determine the heat transfer coefficient and heat transfer area between oil and gas. To simplify the analysis, the heat transfer between oil and gas is classified into two categories in the present study. The first category assumes that the compression room is in oil-injected process, and the heat transfer coefficient is the coefficient between the sphere and the flowing fluid. Based on this assumption, many approximate formulas can be used to describe such a heat transfer mode. Among them, the formula proposed by Ranz in 1952 is adopted in the present paper. It says

$$
N u=2.0+0.6 \operatorname{Re}^{0.5} \operatorname{Pr}^{0.33} .
$$

The heat transfer area is the sum of surface area of all spheres and can be calculated from $A=$ $N_{\mathrm{p}} \pi D_{\mathrm{p}}^{2}$, in which the size of oil drop diameter is calculated by using the mean Sauter diameter formula,

$$
D_{\mathrm{p}}=0.0366\left(\frac{\rho_{\mathrm{l}} \sigma_{1}}{w}\right)\left(1+\frac{m_{\mathrm{g}}}{m_{1}}\right)^{0.7} \text {. }
$$

The number of oil drops, $N_{\mathrm{p}}$, is calculated as

$$
N_{\mathrm{p}}=\frac{6 m_{\mathrm{l}}}{\rho_{\mathrm{l}} \pi D_{\mathrm{p}}^{3}} \text {. }
$$

The second category of heat transfer between oil and gas assumes that the compression chamber is not in an oil-injected process. Under this circumstance, most of the oil is attached to the rotors as well as the case. The heat transfer mode in this 
category is then different from the previously described one. Fujiwara and Osada derived the relationship between the heat transfer coefficient and the volumetric efficiency in the suction process. The formula can be written as

$$
N u=0.51 R e_{\omega}^{0.74}
$$

where

$$
R e_{\omega}=\frac{\omega D_{\mathrm{m}}^{2}}{\mu_{\mathrm{g}}} .
$$

\section{PERFORMANCE SIMULATION AND MODEL TESTING}

Based on the above theoretical analysis, a computer program is written to simulate the performance of a twin screw air compressor. Experimental measurement work (Chen, 1996) has also been performed to test the accuracy of the analytical model. Some of the results are shown in the present section.

\section{Numerical Algorithm}

As indicated by Eqs. (1)-(3) as well as equations for the suction and discharge processes, the governing equations of a twin screw air compressor comprise four nonlinear equations. It is almost impossible to solve them analytically and numerical solution is therefore needed. In the present study, a fourth order Runge-Kutta method is employed. The flow chart of the numerical algorithm is shown in Fig. 2.



FIGURE 2 Flow chart of numerical simulation. 


\section{Model Testing}

Some of the theoretically obtained results such as discharge temperature, volumetric efficiency, compression efficiency and specific power are compared with experimentally measured data (Xiao et al., 1986). Among these data, the volumetric efficiency is defined as the ratio of real amount of discharged gas to the groove volume in the twin screw compressor. The compression efficiency is defined as the ratio of theoretical power consumption to measured shaft horsepower. The specific power is defined as the ratio of the shaft horsepower to the calculated amount of discharged gas. A typical result is shown in Fig. 3. It is found that the volumetric efficiency calculated theoretically is very close to the experimental result. The isothermal efficiency, however, is found to have certain difference between the theoretical and experimental results. The difference becomes significant when the compressor is running at high rotor speed. It may be attributed to the dynamic loss of friction that we did not consider in the theoretical derivation.

From viscous fluid dynamics viewpoint, the consumed energy of the dynamic loss should hold the relationship

$$
E_{\mathrm{d}, 1}=\mu_{\mathrm{m}} \frac{V_{\mathrm{t}}^{2}}{\varepsilon} A_{\mathrm{c}}
$$

in which $\mu_{\mathrm{m}}$ is the mean viscosity of the oil and gas mixture, $V_{\mathrm{t}}$ is the velocity of the tooth tip, $\varepsilon$ is

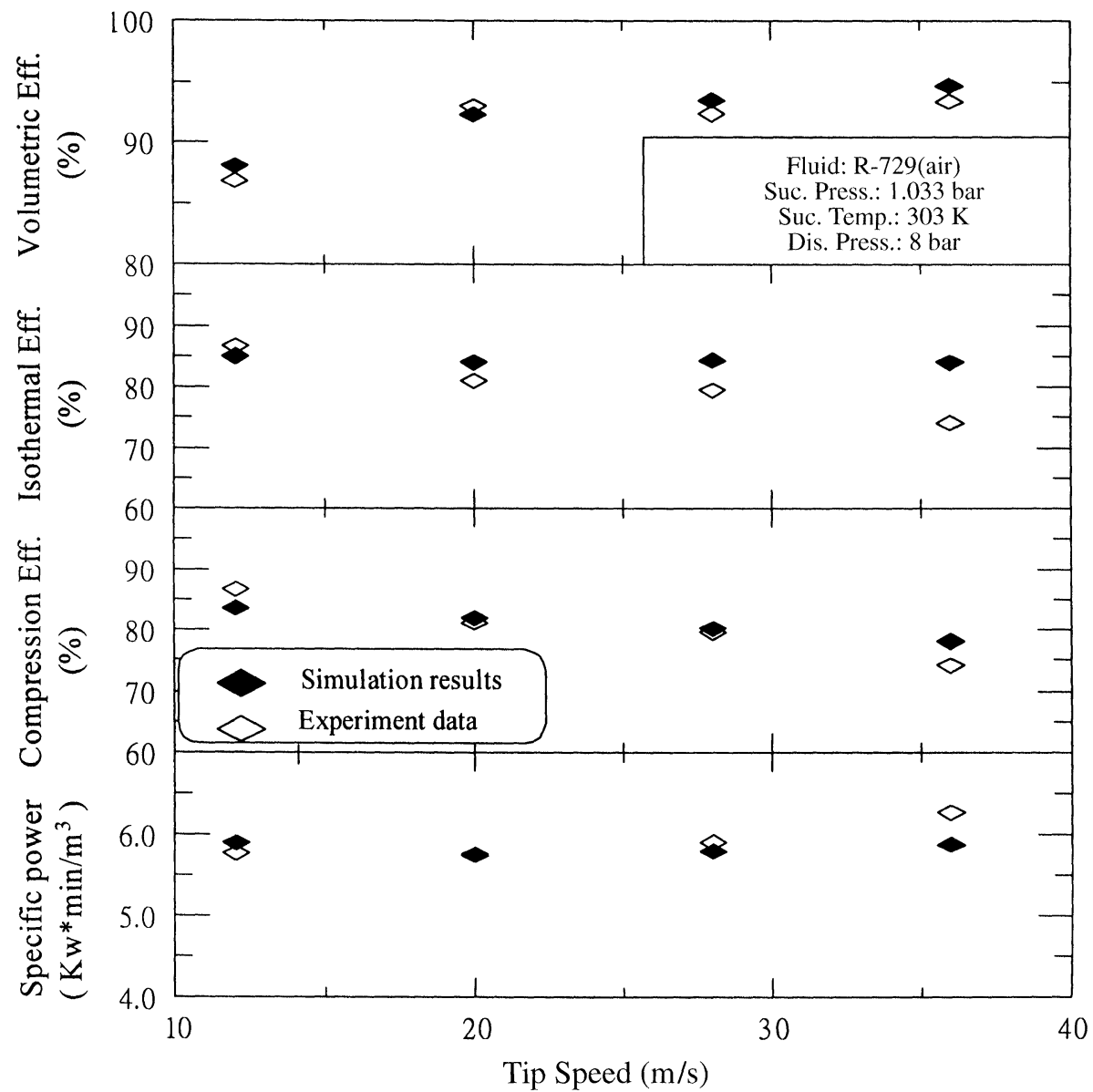

FIGURE 3 Comparison between calculated and experimental results. 


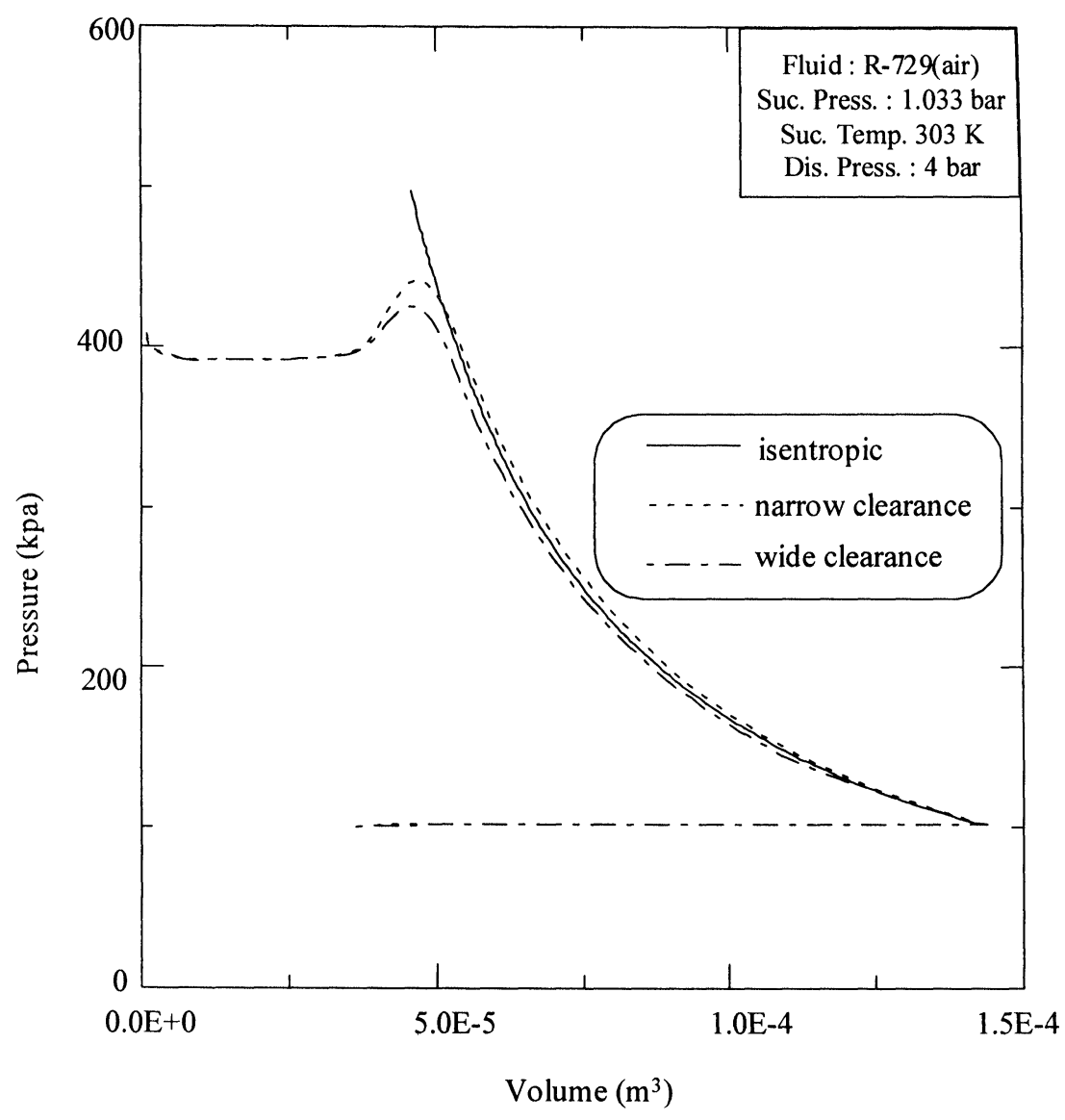

FIGURE 4 Effect of clearance on the performance of an oil-less twin screw air compressor

the clearance between the tooth tip and the case, and $A_{\mathrm{c}}$ is the characteristic area. When the dynamic loss is considered in the present model, the accuracy of the theoretically predicted compression efficiency increases greatly as that shown in the third frame of Fig. 3. Finally, from the last frame of the same figure, it is found that the theoretical values of the specific power are also very close to the experimental data. The accuracy of the above theoretical model is therefore justified.

\section{Performance Analysis of an Oil-Less Compressor}

After justification of the theoretical model, the same analysis is now applied to an oil-less twin screw air compressor in order to study the influence of different design parameters on the performance of the compressor. Among the results, Fig. 4 indicates the influence of gear tooth clearance. It shows that in case that clearance is made wider, the external gas leakage in addition to the internal gas leakage occurs, and the increased amount of leakage makes the pressure distribution to be lower than that of the isentropic process. Figure 5 indicates the influence of rotor speed on the performance of the compressor. It shows that, when the rotor speed increases, the gas leakage decreases and the resulting pressure distribution tends to closer to that of the isentropic process. Under this circumstance, the heating effect diminishes and the amount of gas leakage decreases. As the heating effect and gas leakage are irrevocable factors in the compression process, it implies that the increase of 


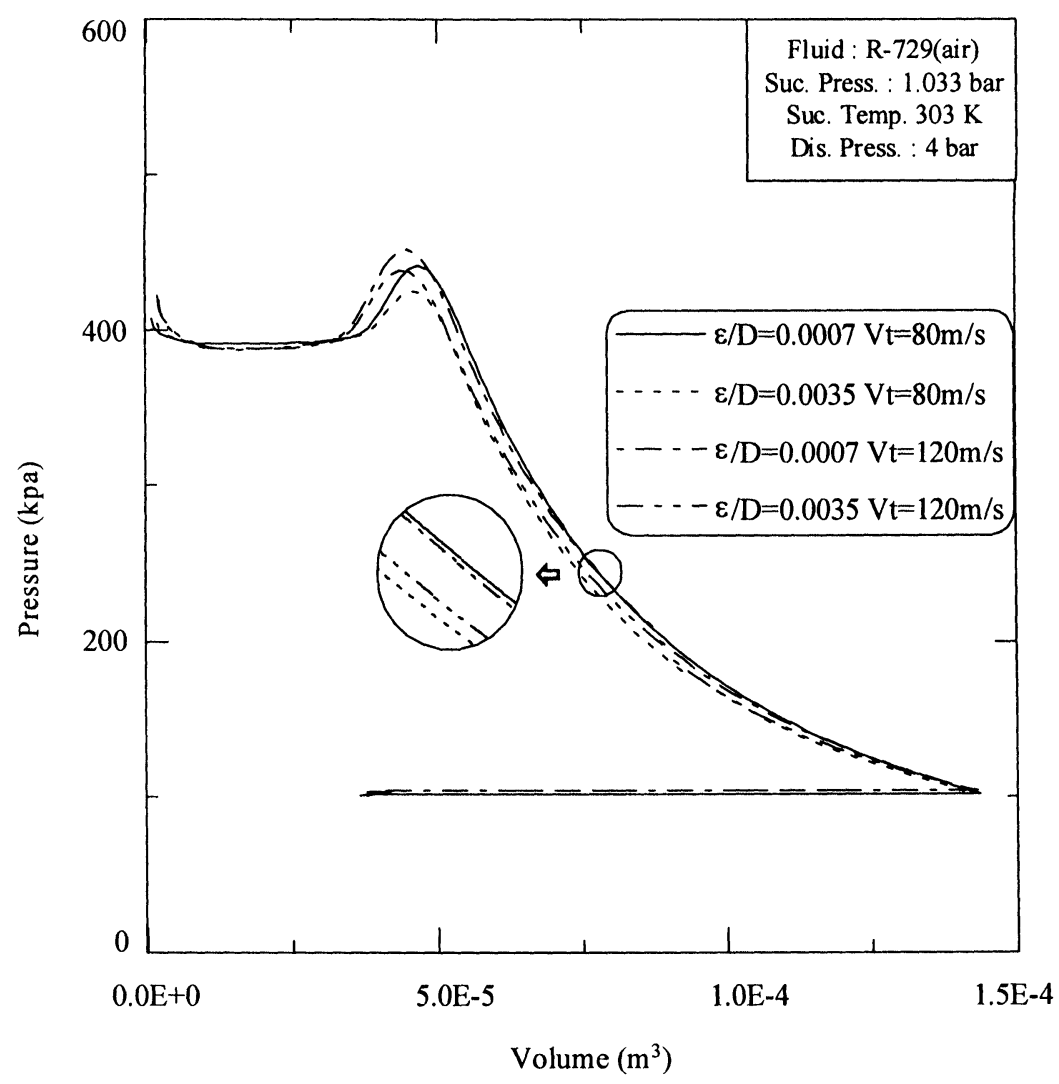

FIGURE 5 Effect of clearance and rotor speed on the performance of an oil-less twin screw air compressor.

\begin{tabular}{|c|c|c|c|c|}
\hline Ratio of clearance to male & \multicolumn{2}{|c|}{0.0007} & \multicolumn{2}{|c|}{0.0035} \\
\hline $\begin{array}{l}\text { Rotor tip } \\
\text { speed }(\mathrm{m} / \mathrm{s})\end{array}$ & 80 & 120 & 80 & 120 \\
\hline $\begin{array}{l}\text { Volumetric } \\
\text { efficiency }(\%)\end{array}$ & 96.36 & 97.61 & 85.52 & 89.95 \\
\hline $\begin{array}{l}\text { Compression } \\
\text { efficiency }(\%)\end{array}$ & 95.89 & 94.67 & 99.81 & 97.51 \\
\hline $\begin{array}{c}\text { Specific power } \\
\left(\mathrm{kW} \min / \mathrm{m}^{3}\right)\end{array}$ & 3.80 & 3.80 & 4.11 & 4.00 \\
\hline
\end{tabular}

rotor speed can reduce the effect of irrevocable factors that make the compression process to be closer to that of the isotropic process. To summarize the result, Table $I$ is constructed and the efficiency as well as the energy consumption data are shown therein.

\section{Performance Analysis of an Oil-Injected Compressor}

In an oil-injected twin screw air compressor, oil plays the role of cooling the compressed gas. It has great influence on the performance of the compressor. Therefore, parameters such as oil flow rate, oil-injected temperature and oil-injected angle have to be considered in the theoretical analysis. Based on the previously proposed model and under the assumption that the rotor speed, suction and discharge pressure, gas temperature and geometric factors are all kept the same as before. Figure 6 shows that the volumetric efficiency becomes higher as the injected temperature becomes lower. This may be attributed to the reduction of leakage driving force due to lower pressure distribution in the compression process. As for the compression 


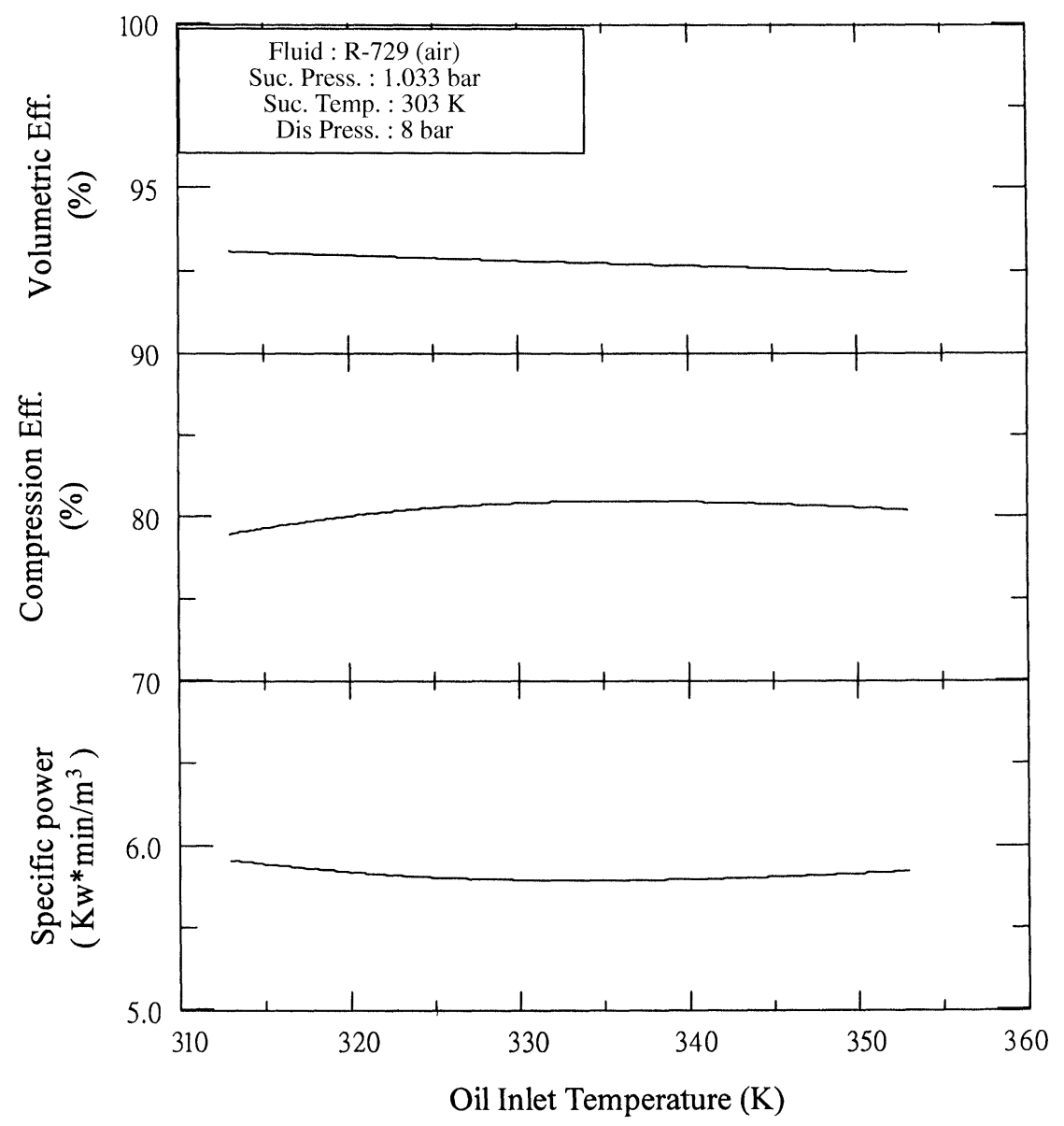

FIGURE 6 Effect of oil inlet temperature on the performance of an oil-injected twin screw air compressor.

efficiency, it is found that higher efficiency is generally obtained as the injected temperature becomes higher. The tendency, however, reverses after the temperature reaches a certain value. The reason is that lower oil temperature in general decreases the work done by the compressed gas. However, it increases the dynamic loss due to higher oil viscosity. An optimal oil-injected temperature may therefore exist as that shown in Fig. 6. Similar situation occurs with regard to the specific power.

The influence of oil flow rate on the compressor performance is shown in Fig. 7. It indicates that both the volumetric and compression efficiency increases as the amount of injected oil increases.
The specific power, however, decreases as the amount of oil increases. The influence of oilinjected angle on the performance of the compressor is shown in Fig. 8. It indicates that the volumetric efficiency decreases but the specific power increases as the oil-injected angle is moved closer to the discharge side. With regard to the compression efficiency, there may be an optimal injected angle as shown in the figure.

For twin screw compressors with fixed suction pressure, the performance of compression is determined by built-in volume ratio and system discharge pressure. The built-in volume ratio of screw compressors is defined as the ratio of volume of the thread at the start of compression process to the 




FIGURE 7 Effect of oil-injection quantity on the performance of an oil-injected twin screw air compressor.

volume of the same thread when it first begins to open the discharge port. For a fixed built-in volume ratio compressor, a mismatch between the internal and system discharge pressures may cause overcompression or undercompression with a resulting decrease in capacity and an increase in power input. Overcompression occurs when the internal pressure in the compression chamber reaches the system discharge pressure before the compressed air arrives at the discharge port. On the other hand, undercompression occurs when the internal pressure reaches the discharge port prior to achieving system discharge pressure.

The relationship between the compression efficiency and compression ratio of various built-in volume ratios is shown in Fig. 9. Four discharge temperatures were considered in the figure, in which the compression ratio is defined as the ratio of the expected suction pressure and to the expected discharge pressure. From the figure it is calculated that, with a fixed built-in volume ratio, the compression efficiency increases along with the increase of the compression ratio. The compressor may have an optimal compression ratio that gives the operation the maximum efficiency. Further increase of the compression ratio will then decrease the compression efficiency. To be more precise, consider the case of Fig. 9(a) that operates at the discharge temperature of $65^{\circ} \mathrm{C}$. If the built-in volume ratio is set to be 3 , the optimal compression ratio is found to be 4.0. In general, the compressors should be designed to match the above-mentioned optimal condition as possible. When the compression ratio is selected to be lower than the optimum point, the compressor is in undercompression condition. On the other hand, 


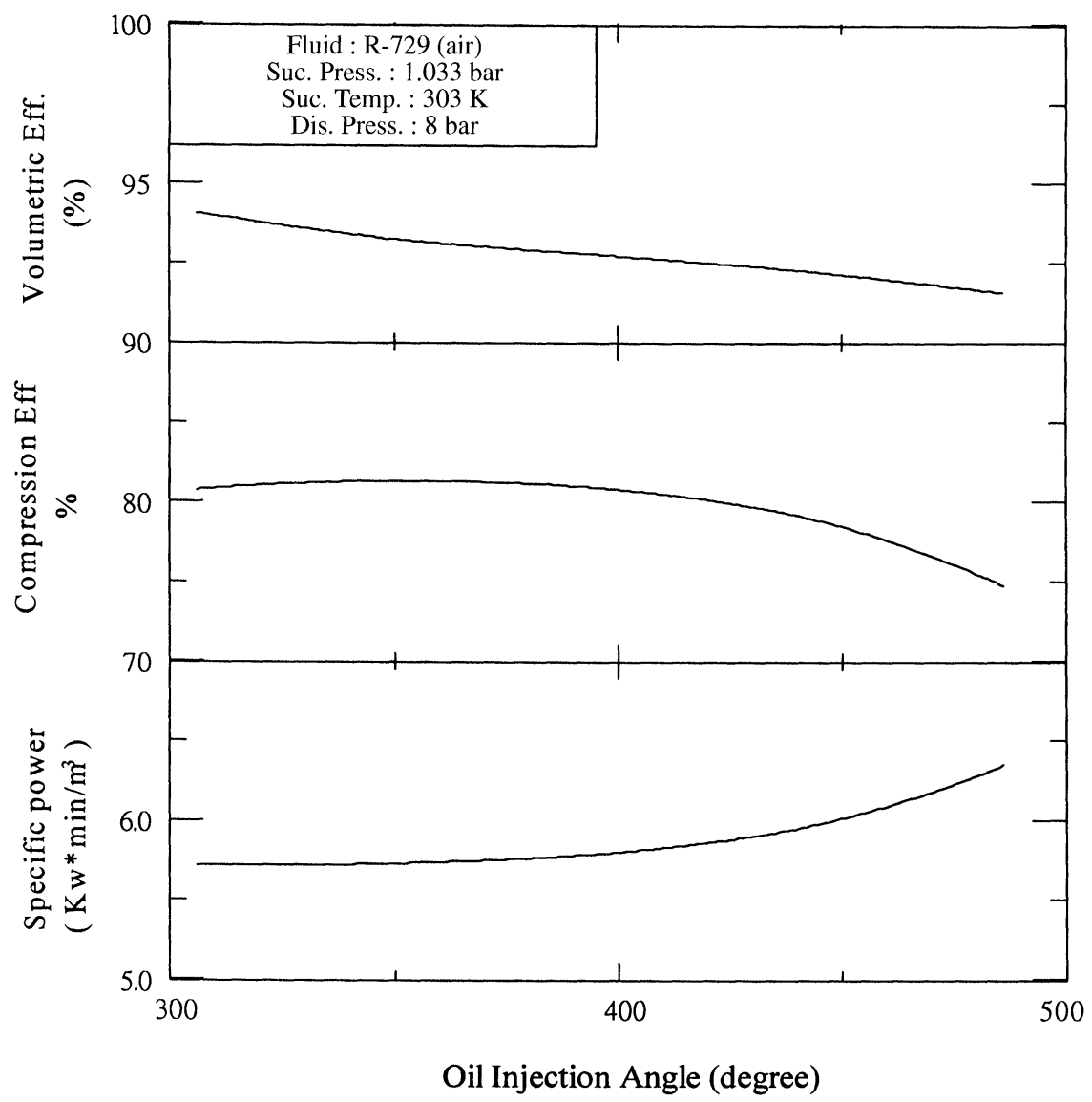

FIGURE 8 Effect of oil-injection angle on the performance of an oil-injected twin screw air compressor.

when the compression ratio is selected to be higher than the optimum point, the compressor then operated in overcompression condition. To summarize the result shown in Fig. 9, it is observed that when the compression ratio is low, better efficiency is usually obtained for lower built-in volume ratios. On the contrary, when the compression ratio is high, better efficiency is obtained at higher built-in volume ratios.

Figure 10 demonstrates the relationship between the optimal compression ratio and the built-in volume ratio for different discharge temperatures. The curves in this figure are plotted based on the optimal design conditions obtained in Fig. 9. The result shows that the optimal compression ratio is linearly proportional to the built-in volume ratio. Although the slopes of these curves are different, their variation is very small. It can be concluded that the optimal compression ratio is insensitive to the discharge temperatures at the temperatures range of $65-80^{\circ} \mathrm{C}$.

\section{CONCLUSIONS}

The following conclusions can be drawn from the present study:

(1) The leakage caused by the clearance can be classified into two kinds, namely external and internal leakage, respectively. When the external leakage is higher than the internal leakage, the pressure distribution is lower than that of the isentropic process. Conversely, when the 

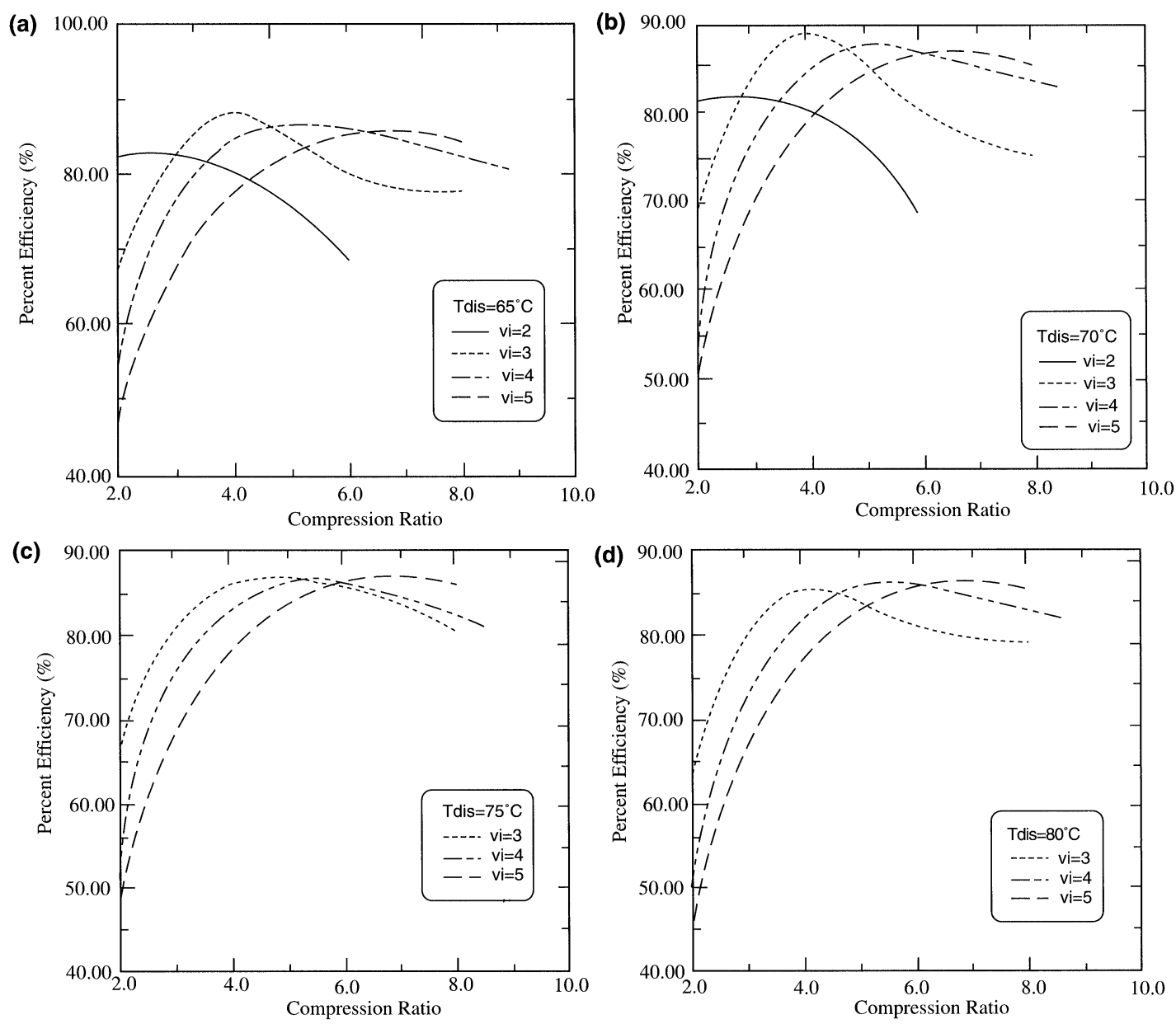

FIGURE 9 Effect of compression ratio on the percent efficiency at various built-in volume ratios; $T_{\mathrm{d}}$ for (a) $65^{\circ} \mathrm{C},(\mathrm{b}) 70^{\circ} \mathrm{C}$, (c) $75^{\circ} \mathrm{C}$, and (d) $80^{\circ} \mathrm{C}$.

external leakage is lower than the internal leakage, the pressure distribution will be higher than that of the isentropic process. Higher rotor speed can also reduce the leakage and make the compression process move toward the isentropic process.

(2) The volumetric efficiency of a screw compressor can be improved by raising the injected oil temperature and making the discharge temperature lower. As for the energy consumption, there may exist an optimal injected temperature that results in the highest compression efficiency and the lowest specific power.
(3) The oil-injected angle is irrelevant to the discharge temperature, but it has great influence on the distribution of pressure and temperature. Better volumetric efficiency can usually be achieved by the selection of an earlier oilinjected angle.

(4) For a fixed volume ratio, there exists an optimal compression ratio that result in the maximum compression efficiency. For a fixed compression ratio, depending on the compression ratio the maximum compression efficiency may be higher or lower as the build-in volume ratio becomes higher. 


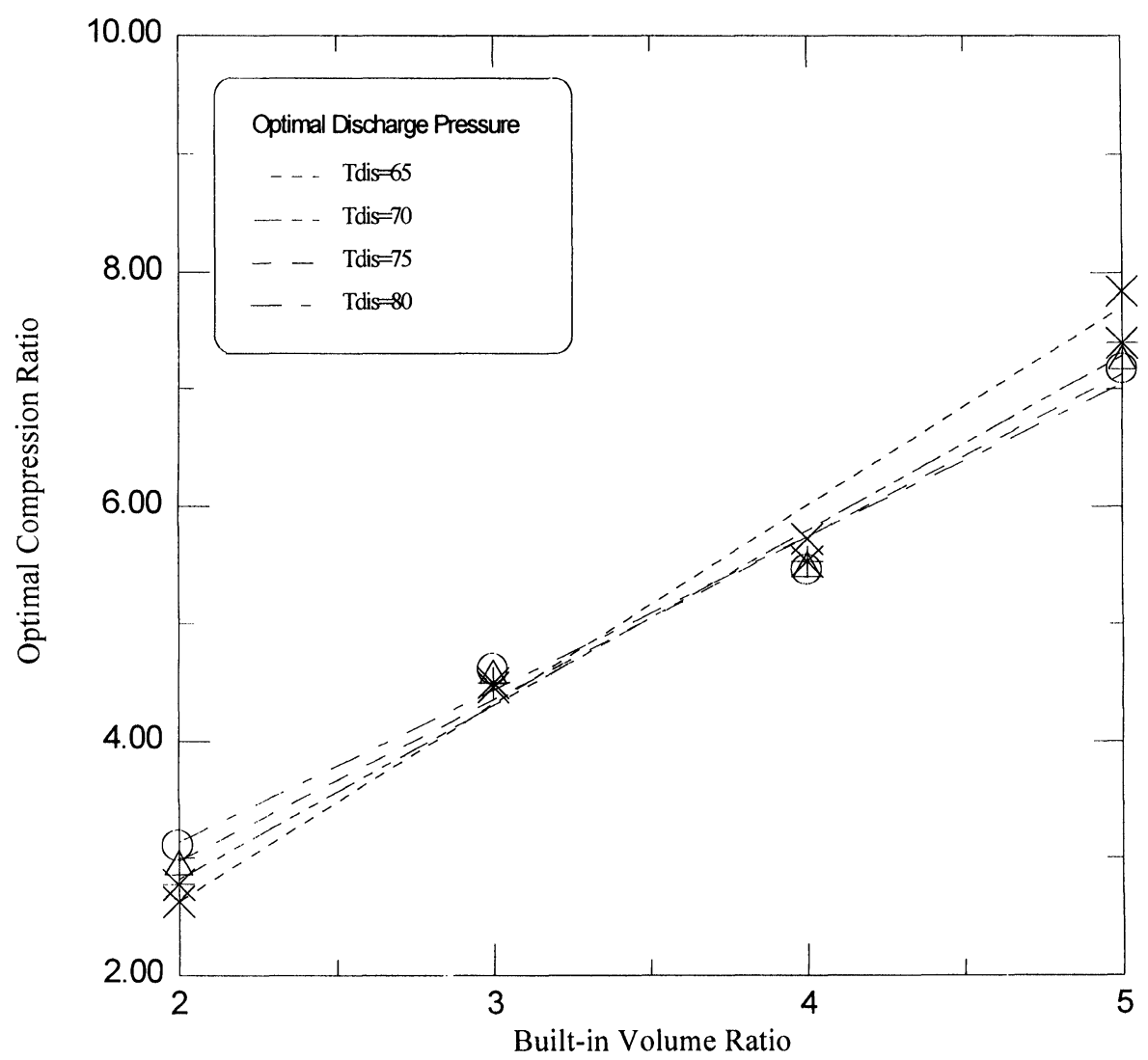

FIGURE 10 Relation of optimal compression ratio and built-in volume ratio at various discharge temperatures.

\section{NOMENCLATURE}

\section{$A \quad$ Area $\left(\mathrm{m}^{2}\right)$}

$A_{\mathrm{c}} \quad$ Characteristic area $\left(\mathrm{m}^{2}\right)$

$A_{\mathrm{v}} \quad$ Valve area $\left(\mathrm{m}^{2}\right)$

$C_{\mathrm{D}} \quad$ Coefficient of flow rate

$C_{\mathrm{P}} \quad$ Specific heat at constant pressure $(\mathrm{KJ} / \mathrm{kg} \mathrm{K})$

$C_{\mathrm{v}} \quad$ Specific heat at constant volume $(\mathrm{KJ} / \mathrm{kg} \mathrm{K})$

$D_{\mathrm{p}} \quad$ Mean Sauter diameter

$E_{\mathrm{d}, 1} \quad$ Dynamic loss (KJ)

$h \quad$ Heat transfer coefficient $\left(\mathrm{W} / \mathrm{m}^{2} \mathrm{~K}\right)$

$i \quad$ Specific enthalpy $(\mathrm{J} / \mathrm{kg})$

$m \quad$ Mass $(\mathrm{kg})$

$N_{\mathrm{p}} \quad$ Number of oil drops

$\mathrm{Nu} \quad$ Nusselt number
$P \quad$ Pressure $(\mathrm{Pa})$

$\mathrm{Pr} \quad$ Prandtl number

$R \quad$ Universal gas constant $(\mathrm{KJ} / \mathrm{kg} \mathrm{K})$

$R_{\mathrm{m}} \quad$ Revised gas constant $(\mathrm{KJ} / \mathrm{kg} \mathrm{K})$

Re Reynolds number

$R e_{\omega} \quad$ Rotational Reynolds number

$T \quad$ Temperature (K)

$V \quad$ Volume $\left(\mathrm{m}^{3}\right)$

$V_{\mathrm{t}} \quad$ Rotor tip velocity $(\mathrm{m} / \mathrm{s})$

$w \quad$ Flow rate $(\mathrm{m} / \mathrm{s})$

$x, y, z \quad$ System coordinates

\section{Greek Symbols}

$\beta \quad$ Modified specific heat rate

$\varepsilon \quad$ Clearance (m)

$\phi \quad$ Ratio of oil mass to gas mass 
Efficiency

Pressure angle (rad)

Dynamic viscosity $(\mathrm{kg} / \mathrm{m} \mathrm{s})$

Density $\left(\mathrm{kg} / \mathrm{m}^{3}\right)$

Surface tension $(\mathrm{N} / \mathrm{m})$

Rotor speed ( $\mathrm{rad} / \mathrm{s})$

\section{Superscript}

- Physical quantity per unit time

\section{Subscript}

d Discharge side

f Female rotor

g Gas

1 Oil, Low pressure side

$\mathrm{m} \quad$ Male rotor, Mean value

s Suction side

\section{References}

Bein, T.W. and Hamilton, J.F., 1982, Computer modeling of an oil flooded single screw air compressor, Proc. Int. Compressor Engineering Conf., Purdue, USA, pp. 127-134.

Chen, S.L. and Wu, W.F., 1996, Performance Simulation and Experimental Testing of Twin Screw Compressors, Technical Report, Department of Mechanical Engineering, National Taiwan University, Taipei, Taiwan.

Fujiwara, M. and Osada, Y., 1995, Performance analysis of an oil-injected screw compressor and its application, Int. $J$. Refrig., 18(4), 220-227.

Sångfors, B., 1982, Analytical model of helical screw machines for analysis and performance prediction, Proc. Int. Com pressor Engineering Conf., Purdue, USA, pp. 135-139.

Singh, P.J. and Bowman, J.L., 1986, Effect of design parameters on oil-flooded screw compressor performance, Proc. Int. Compressor Engineering Conf., Purdue, USA, pp. 71-88.

Xiao, D., Xiong, Z. and Yu, Y., 1986, The computer simulation of oil-flooded refrigeration twin-screw compressors, Proc. Int Compressor Engineering Conf., Purdue, USA, pp. 349-361. 

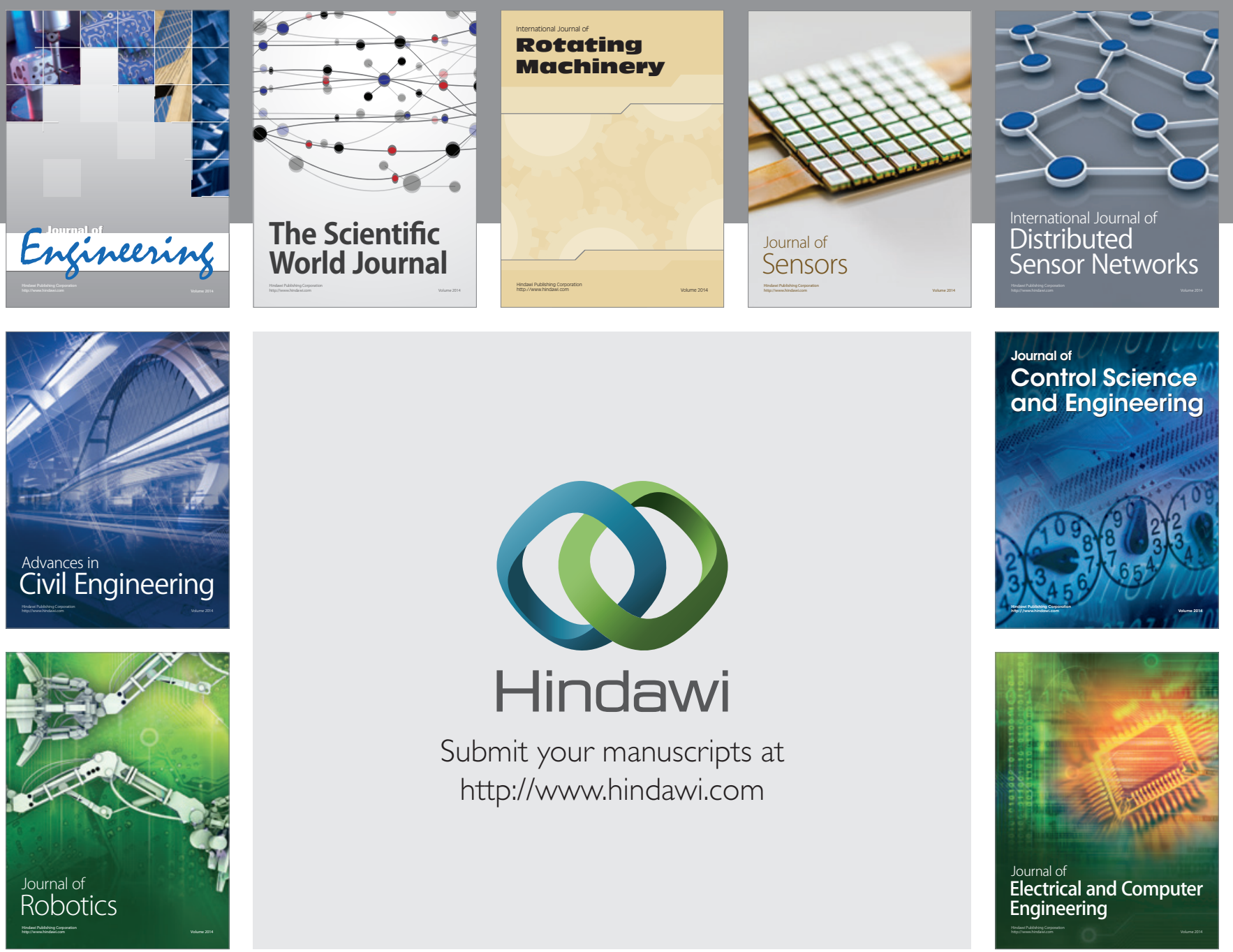

Submit your manuscripts at

http://www.hindawi.com
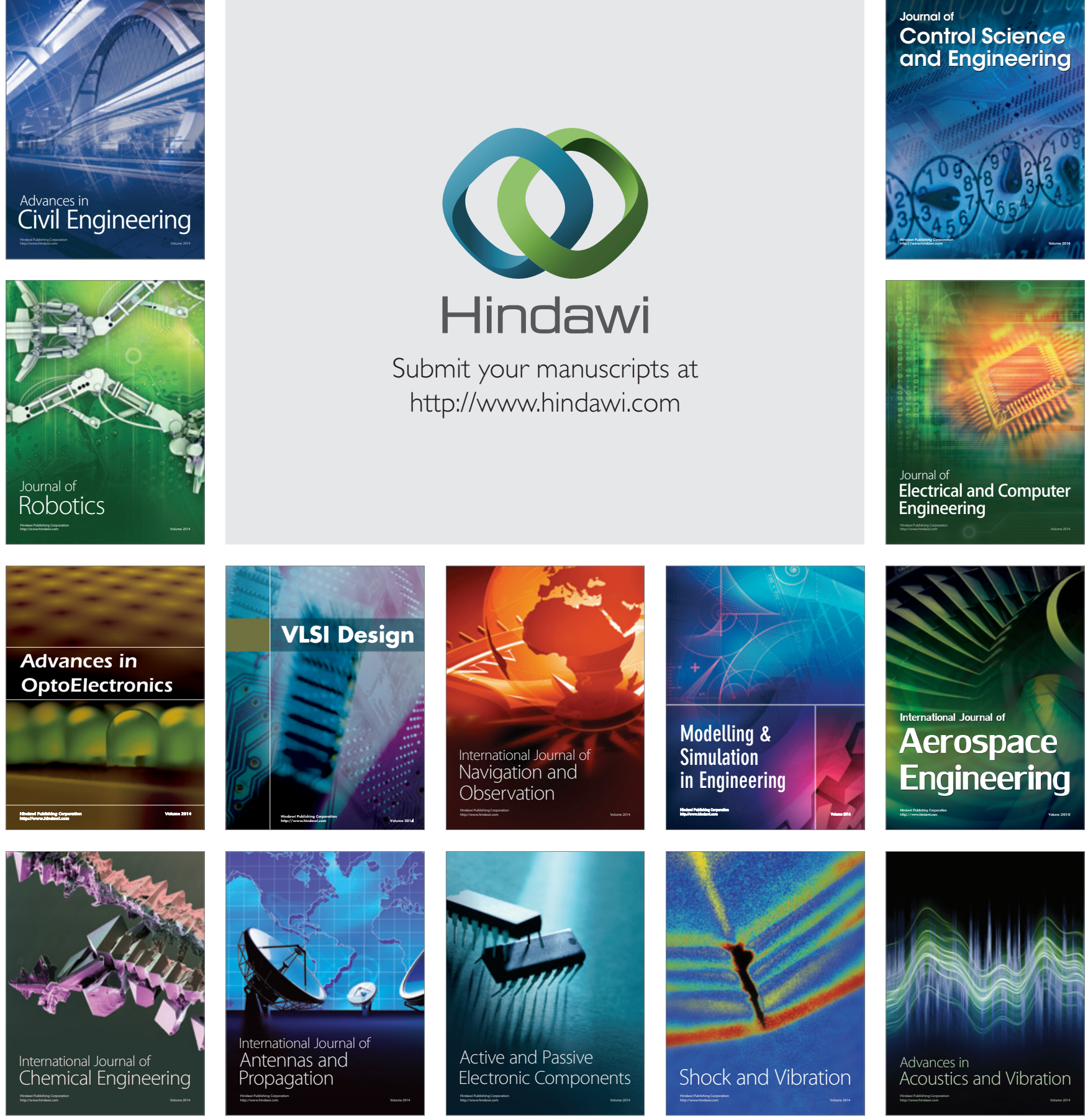